\title{
Universal Skills Framework for Migrants, Asylum Seekers and Refugees - A Mapping on the Required Skills While Entering the European Labour Market
}

\author{
Maria Tountopoulou ${ }^{1}$, Fotini Vlachaki ${ }^{1}, \&$ Maria-Eirini Triantafillopoulou ${ }^{1}$ \\ ${ }^{1}$ Ison Psychometrica, Greece \\ Correspondence: Maria Tountopoulou, Ison Psychometrica, Greece.
}

Received: March 5, 2021

doi:10.11114/ijsss.v9i3.5181

\author{
Accepted: March 30, 2021 \\ Available online: April 13, 2021 \\ URL: https://doi.org/10.11114/ijsss.v9i3.5181
}

\begin{abstract}
Migration flows are steadily increasing worldwide. Especially in Europe, the percentage of immigrants from third countries generally ranges from $9 \%$ to $17 \%$. As one of the main factors that plays an important role in the overall integration of migrant groups in host countries is their ability to work, there is an emerging need for effective policies and mechanisms to identify and certify skills and qualifications of migrants, asylum seekers and refugees in order to enable them to integrate effectively into the labor market.

Many existing skills frameworks at European and international level emphasize the importance of cognitive skills as well as non-cognitive skills, attitudes and also the crucial role of personality traits that determine the success and employability of the workforce. A framework for universal skills is proposed based on a thorough literature review of the existing international frameworks and of the skills and competencies required to integrate into the labor market. In addition, a field survey with a structured questionnaire was conducted with both employers and migrant groups, to capture the views of both on the selected skills included in the framework and to confirm the extent to which those skills are considered important towards the labor market integration of migrant groups in the host countries.

The results of the research highlighted on one hand the importance of hard skills required to perform a task and on the other hand the soft skills that are of particular importance regardless of the profession. Moreover, a high majority of both groups stated that skills profiling and online assessment tools that matches skills with labour market needs would be valuable in recruiting procedures.
\end{abstract}

Keywords: labour market integration, migrants, refugees, asylum seekers, skills

\section{Introduction}

\subsection{Recognition and Accreditation of Migrant Groups 'Skills}

In the last decade there has been a worldwide increase in the number of migrant groups, which is unprecedented and even exceeds the corresponding numbers after the Second World War. The number of international migrants is estimated to be almost 272 million globally, with almost two-thirds being labour migrants (UN DESA, 2019). Furthermore, migratory flows have undergone variations, moving toward regions able to offer more job opportunities (Mucci et al., 2019). Acquired skills, qualifications and competencies are an asset for migrants' labour and social integration. As migration is expected to continue growing all over the world, new opportunities are created for improving the recognition of skills across borders and the deployment of skilled labour in order to enhance their potential to contribute to development objectives in hosting countries.

Worldwide there is a focus on policies and practices regarding the identification, recognition and accreditation of skills, qualifications and competencies, so as to enable effective labour market integration and capitalize on the benefits of migration for individuals, societies and countries. It is indicative that among the issues discussed on the 106th session of the International Labour Conference (June 2017), skills recognition and development for migrant workers was prioritized, particularly for the migrant workers who are dealing with limited access to such services as recognition of prior learning. It was stressed that it is crucial to facilitate the recognition, certification, accreditation and use of skills and qualifications of refugees as well as to provide refugees with access to tailored training and retraining opportunities (International Labour Organization, 2017a, b). 
The recognition of qualifications and experience has been identified as a "central immigration issue of the new century ... in all post-industrial societies receiving immigrants" (Cameron et al., 2019). The development of workforce skills is an important asset for migrants' work and social integration and plays a vital role in productivity enhancement and sustainability in both countries of destination and origin. Migrant groups frequently encounter difficulties in articulating and demonstrating their experiences acquired in their countries. Migrants' home country qualifications and work experience might often not be fully transferable to the destination country (Př́vara, Rievajová, \& Yüceşahin, 2019).

Those whose qualifications and work experience are not adequately -if not at all-recognised in host countries will often experience skill wastage and exploitation. For many skilled migrants, refugees, asylum seekers, this creates a barrier for securing employment commensurate with qualifications and experience and thereby creates skills wastage and downward mobility (Cameron et al., 2019). It is acknowledged that migrant groups possess competencies and abilities acquired in their home country or in the hosting countries, which are not formally mapped, assessed, certified or acknowledged. This may result in reduced prospects for finding employment and better working conditions. At the same time, countries' capacity to build a skilled and qualified workforce is eliminated (Bardy et. al., 2017; Dall'Amico \& Verona, 2015; ILO, 2015). Moreover, difficulties in migrant groups' skills identification often cause poor "quality of employment" which has negative consequences on the migrant employees such as work-related stress (Mucci et al., 2019).

The universality of skills needed also for migrant groups is also highlighted, as migrants and refugees face the same challenges in the European labour market as the wider segment of the working population and they need the same skills enabling them to maintain work integration and employability in the rapidly changing world of work. According to ILO many migrants and refugees will be facing the same situation in the European labour market as the wider segment of the working population and they will also need specific skills enabling them to navigate themselves in the world of near-infinite information and rapid change. Skills such as critical thinking, complex problem-solving, self-motivation to learn, resilience and ability to negotiate change as well as digital skills are very important, especially for newcomers, with integration-related informational materials and learning opportunities increasingly being made accessible online (ILO, 2017b). Furthermore, the existing approaches to soft skills demonstrate that the perception of its value extends across cultures, economies, and business development practices, as companies in a global marketplace are turning to soft skills development in order to remain agile and responsive to customer expectations and optimize their potential for sustained performance and growth. In this respect there is an increasing widespread recognition of a correlation among a set of universal skills including strengthened communication, interpersonal, and social skills and enhanced customer relationships, improved collaboration and productivity, and increased employee engagement and teamwork (The Adecco Group, 2017).

On the other hand, it was recently highlighted that "the employment systems of the host countries operate according to the logic of national labour markets, entailing institutionally and culturally specific skill expectations as well as formation processes", causing entry failure or the downgrading of migrant groups in the process of entering the local labour market (Liu-Farrer \& Shire, 2020). In addition, it is argued that identifying workers' transferable skills is difficult for organizations in general (Bernhard-Oettel \&Näswall 2015), while restructuring personal assets and reassessing previous training and work experience between contexts is problematic (Eggenhofer -Rehart et al., 2018; Mancinelli et al., 2010; van Riemsdijk et al., 2016).

Additionally, according to a skill-based approach initiated by Cedefop in collaboration with the International Centre for Migration Policy Development, skills are considered as a key to migrant/refugees' integration in the host countries, allowing for labour mobility, effective resettlement and matching with host countries' skills shortages and local labour market needs. Also, skills based pathways would give the opportunity to refugees for personal and career development according to their potential, while at the same time would enable socially sustainable solutions to improve the refugee crisis' management in EU Member States (David \& Katsikis, 2019; David \& Wagner, 2019).

Despite the importance of skills recognition and certification, there are still difficulties in establishing skills identification and assessment processes all around Europe due to the lack of a uniform definition of "skills" (International Labour Organization, 2015). It is obvious that the relevant practices for skills identification in EU countries are still constrained and so does the access to such services, especially for low- and medium-skilled migrants, asylum seekers and refugees. The dynamic nature of labour markets due to economic globalization makes the exercise of skills identification and skills matching even more challenging for both potential and return migrants, as in many origin countries, skill forecasting or skill assessment methods are either non-existent or implemented on a limited basis. In this respect, it seems there is an urgent need to develop meaningful relevant assessment tools, methods and techniques to measure and recognize the migrant workers' skills. These have to be based on cross-national cooperation, so as to enable deploying them and linking them to meaningful employment outcomes, in favour of the individuals' and 
society prosperity.

Grounded on the emphasis placed internationally at skills identification and on the fact that there appears a lack of tools for recognising hard, soft and informal skills, ensuring the transferability of those practices among European Union (EU) Member States (Marangozov, 2017), one major goal of the research conducted within H2020 NADINE Project is to develop a Universal Skills Framework that would be the basis for the assessment and recognition of migrant groups' skills and competencies.

Therefore, the purpose of this article is to present the developed Universal Skills Framework and the results from the surveys conducted with employers and migrant groups. The main objective of the survey with employers was to confirm or not the suitability of the NADINE Universal Skills selected as well as identify the hard and soft skills that are considered important in the labour market, so as to improve the inclusion of migrants and refugees in the host communities. In addition, the aim of the survey involving migrants, asylum seekers and refugees was to get information directly from the end-users, concerning the hard and soft skills that are considered important in the labour market, based on their former experience in the origin countries and their efforts for labour market inclusion in the host communities.

\subsection{Universal Skills Framework}

Skills are recognised as extremely important in the modern economy and in everyday life, especially within the on-going structural changes in the global labour market and rapid technological change, as well as demographic changes, with ageing populations, and workforce's migration. According to European Qualifications Framework (EQF) definition "skill means the ability to apply knowledge and use know-how to complete tasks and solve problems. They can be described as cognitive (involving the use of logical, intuitive and creative thinking) or practical (involving manual dexterity and the use of methods, materials, tools and instruments)" (European Commission, 2017).

Skills are distinguished in generic skills, used in a variety of occupations and professional skills related to a specific profession. According to CEDEFOP's Skills Panorama glossary (2020), basic skills are those needed to live in contemporary society, e.g. listening, speaking, reading, writing and mathematics, while hard skills are strictly job-specific, closely connected with knowledge, easily observed, measured and trained. Soft skills are non-job specific, are cross-cutting across jobs and sectors, closely connected with intangible personal attitudes and competences, such as confidence, discipline, self-management and social competences, such as teamwork, communication, emotional intelligence.

At European but also international level there are different perceptions and approaches to the definition of "soft skills'. Soft skills are considered as equally important to hard skills when looking for a job, while they are more difficult to be demonstrated and measured and employers cannot easily identify them. Soft or transferable skills mostly refer to flexibility and adaptability, interpersonal and communication skills, problem solving, creativeness, team working skills, initiative, leadership, creativity, self-motivation, time management and the ability to make decisions. Personal skills and attitudes are as important to employers as their vocational counterparts and are considered necessary in different work settings and important in order to achieve employability and active participation in the labour market as well as the effective management of personal and social life (life skills) (Brewer, 2013; Cedefop, 2013).

Literature review revealed a wealth of skills definitions and frameworks, both at European and international level, highlighting different perceptions and approaches related to the indispensable qualities pertaining to labour market participation, employability and social participation. The existing competence frameworks at European and international level which highlight the core skills needed for labour market integration include: the OECD DeSeCo conceptual framework for key competencies (2005), OECD Competency Framework (2014), OECD PISA Global Competency Framework (2018a), the ILO Regional Model Competency Standards (RMCS) for Core Competencies (2015), the European Reference Framework for Key Competences for Lifelong Learning (European commission, 2018a), the multilingual classification of European Skills, Competences, Qualifications and Occupations (ESCO_ European Commission, 2019b), the European Digital Competence Framework for Citizens (DigComp) (European Commission, 2018b), the Entrepreneurship Competence Framework (EntreComp) (European Commission, 2019a), the Council of Europe Competences for Democratic Culture (2016), the UNESCO Intercultural Competences Framework (2013a), the UNESCO Global Framework of Learning Domains (2013b), the Behavioral Competencies Personality Traits of the OECD PIAACC survey (2016), the OECD Learning Framework 2030 (OECD, 2018b).

The analysis of all these definitions and frameworks indicated that these competence frameworks highlight the importance of a grid of hard skills and soft skills, attitudes or values and personality characteristics that can -to a certain degree- define workforce success and employability in the globalised labour market. The competence frameworks define the essential knowledge, skills and attitudes for adequate performance and integration in the 
globalized labour market and encourage the assessment and validation of competence development (European Commission, 2018a). Based on the literature review findings there is a general consensus that, hard skills, mainly related to language literacy, numeracy, digital literacy and technical skills, as well as soft skills, including interpersonal communication skills (e.g. team-working), personal skills (e.g. adaptability), organizational skills (e.g. time management) and cognitive-analytical skills (e.g. decision making) are capabilities and characteristics that equip individuals to participate effectively in a wide range of social settings, including workplaces and adult life more generally. Competencies such as openness to change, organisational skills and responding to fast changing digital and technological environments are included in all competence frameworks. Also, skills, such as critical thinking, creativity and problem solving, are featured prominently in all competence frameworks. The intercultural competence is also highly acknowledged as a global competence that can boost employability and effective collaboration within diverse teams, while entrepreneurship competence, are considered important to all spheres of life, facilitating personal and career development as well as active participation in society. In addition, prosociality involves advanced personal and interpersonal skills, including empathy and active concern for the rights, feelings, and welfare of other people, self-regulation of one's behavior, emotions, and thoughts, social competence, collaboration and communication skills, ability to deal with multi-level conflicts, conscientiousness, adaptability, reliability and trustworthiness. These skills are highly meaningful for migrant/refugee groups in terms of their social adjustment and effective integration, achievement of peer acceptance among natives, and need to feel affiliated and belongingness into the host society (Keltner et. al, 2014; Penner et. al, 2005; Strohmeier et. al., 2012; Baert, S., \& Vujić, S., 2016; Wibisono et. al., 2019; Schippers et. al, 2001; Louis et.al., 2019).

In this respect, NADINE project with the aim to develop a comprehensive model of skills assessment and profiling and following a thorough literature review on identifying the hard and soft skills needed in the labour market proposes a relevant Common Framework for migrants' / refugees' skills. The common important elements that were taken into account based on the existing skills definitions and frameworks in order to construct the NADINE Universal Skills Framework for migrants \& refugees are the following:

- Definition: The skill has a commonly used and understood definition based on the literature review of relevant surveys and existing frameworks internationally.

- Amplitude: The skill is either strictly job-specific across occupational sectors (hard skills) or closely connected with intangible personal attitudes and competences (soft skills).

- Transferability/ portability: The skill can be applied to a wide range of different jobs and industries and can be transferred from one job to another.

- Relevance to the future work challenges: The skill, alone or in combination with others, equip people for future employment challenges in a globalised labour market.

- Relevance to migrant populations: The skill is meaningful for labour migration and social /labour market integration of migrants and refugees.

- Universality: The skill is reported to be important globally and across different countries of origin and destination.

- Impact: The skill is proven to have an impact on life and employment outcomes.

- Interdependency: The skill can be developed in conjunction with others.

- Malleability / Learnability: The skill can be developed or improved through the processes of learning or can be acquired through informal pathways.

- Measurability: The skill can be given a comparative numerical value on a scale, or a non-numerical account.

Based on the international existing competency frameworks analysis and relevant competency classifications (e.g. ESCO) a Universal Skills Framework for migrants \& refugees was developed (table 1). 
Table 1. NADINE Universal Skills Framework

\begin{tabular}{|l|}
\hline \multicolumn{1}{|l|}{ OVERVIEW OF THE NADINE FRAMEWORK FOR MIGRANTS' / ASYLUM } \\
SEEKERS'/ REFUGEES' UNIVERSAL SKILLS \\
\hline 1. Language learning aptitude \& literacy skills \\
\hline 2. Numeracy skills \\
\hline 3. Mechanical skills \\
\hline 4. ICT skills \\
\hline 5. Technical skills: Dexterity, Accuracy, Spatial ability \\
\hline $\begin{array}{l}\text { 6. Interpersonal skills: Social interaction/communication, Team working, Conscientiousness, Coping with } \\
\text { authority, Intercultural competence, Extraversion }\end{array}$ \\
\hline 7. Organizational skills: Independent work, Organization, Work efficiency, Time management \\
\hline 8. Cognitive/ Analytical skills: Decision making, Problem solving, Observational skills \\
\hline 9. Personal skills: Adaptability, Reliability, Willingness to learn, Stress tolerance \\
\hline 10. Entrepreneurial - Intrapreneurial skills: Creativity, Initiative, Managerial skills, Risk tolerance, \\
Leadership
\end{tabular}

More specifically, the NADINE framework includes 10 business-oriented universal hard and soft core skills and respective 25 sub-skills (totally 35 dimensions), with the aim to serve as a comprehensive model for the assessment and profiling of migrant groups' skills in the process of their labour market integration in todays' globalised labour market.

The framework embraces commonly used and understood definitions for each selected skill and sub-skill linked to relevant learning and labour outcomes, as well as intangible personal traits, which are applicable and transferable to a wide range of different jobs and industries. The proposed framework also ensures the interdependency, malleability-learnability and measurability of the skills and sub-skills selected so as to provide an accurate and useable skills profiling platform for migrants/refugees labour market integration purposes.

\subsection{Research Questions}

The relevance, completeness and appropriateness of the proposed Universal Skills Framework was assessed after research conducted with the participation of employers and migrant groups, in $5 \mathrm{EU}$ countries. The research explores the following questions: a Which are the most important skills for the integration of migrants / refugees/asylum seekers into the labour market in the host countries according to employers? b. Which are the most important skills for migrants'/refugees'/asylum seekers' labour market integration according to migrant groups? c. Are the skills included in the proposed Universal Skills Framework in tune with employers' views? d. Are there differences in skills that are considered significant in the different EU countries? e. Which are the most important recruiting criteria? f. Do employers and/or migrant groups are in favour of assessment tools in recruitment?

\section{Method}

\subsection{Measures and Data Collection Process}

Taking into consideration the development of the NADINE Universal Skills Framework for migrants \& refugees, the NADINE team implemented a structured participatory research strategy to enable representatives from enterprises, public authorities, NGOs, and other entities, to express their opinion concerning the skills that are in demand and in that way verify the desk research results on the universal skills that are needed for migrants', refugees' and asylum seekers' labour market integration.

Considering the difficulty to reach employers and relevant stakeholders, and even more due to the COVID-19 pandemic, an on-line questionnaire in English and Greek language was created and sent to several organisations, among the contact lists of consortium's partners. The questionnaire was developed taking into account the theoretical background of the proposed Universal Skills Framework and the relevant literature review for the skills required in the labour market. In order to ensure the effective participation of as more entities as possible, the anonymity of the participants was safeguarded as no personal information or the name of the organization were required.

Relevant information was also directly derived from migrants, asylum seekers and refugees asking them about the hard and soft skills that are considered important in the labour market and employers request from them, based on their former experience in the origin countries and their efforts for labour market inclusion in the host communities.

Accordingly, a paper based anonymous questionnaire in English \& Greek language served as a guide for the implementation of assisted focus groups/ interviews that involved migrants and refugees in cooperation with 
relevant services in each country. A special effort has been made to involve both working and unemployed migrants/ refugees and asylum seekers. In order to overcome linguistic barriers, the implementation of the assisted focus groups or individual interviews was assigned to experienced cultural mediators. Specifically, they undertook to ask the questions and provide the relevant explanations needed to the migrants/ refugees/ asylum seekers. The answers of the participants were recorded by the facilitators where poor language skills were detected.

The process for both groups involved two cycles of data collection, in March-May 2019 and November 2019 March 2020.

\subsection{Participant Characteristics}

\subsubsection{Employers' Characteristics}

In the survey were involved in total 122 entities out of 200 that were invited to answer the questionnaire.

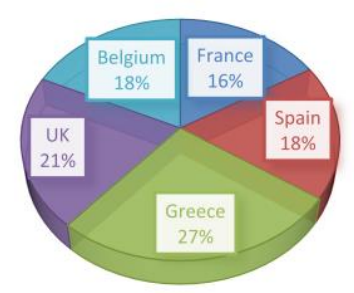

Figure 1. Country of the participating entities

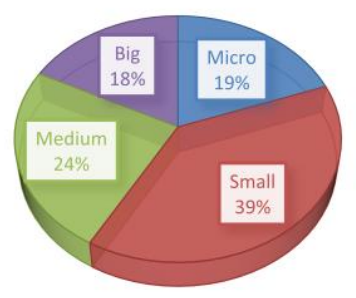

Figure 2. Size of organisation

Regarding the country of participants $27 \%$ were from Greece, $21 \%$ from UK, $18 \%$ from Belgium, $18 \%$ from Spain and $16 \%$ from France (Figure 1). Most of the participating entities represent Small and Medium Enterprises (62\%), while $36 \%$ represent larger companies (Figure 2).

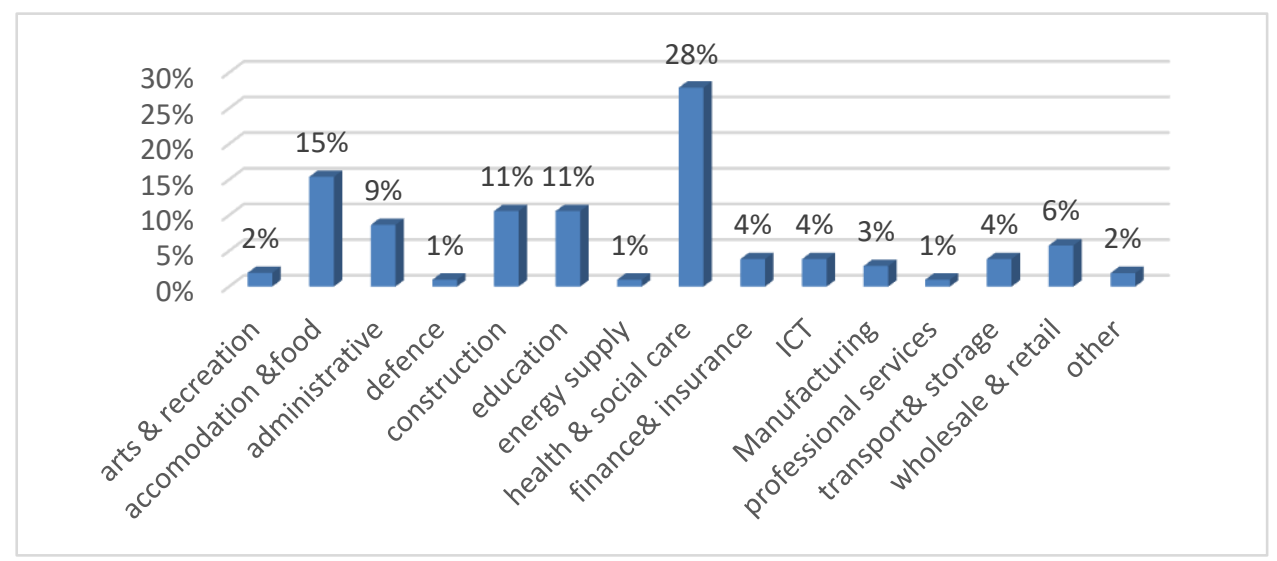

Figure 3. Sector of activity of the participating entities

As of the sector of activity $28 \%$ were from health and social care, $15 \%$ Accommodation, $11 \%$ Education, $11 \%$, Construction, 9\% Administrative services, $6 \%$ Wholesale and retail trade, 4\% Finance \& Insurance, Transportation, ICT services, 3\% Manufacturing, 2\% Arts and recreation, $1 \%$ Defense, Energy supply \& Professional Services and $2 \%$ other (charity) (Figure 3). 


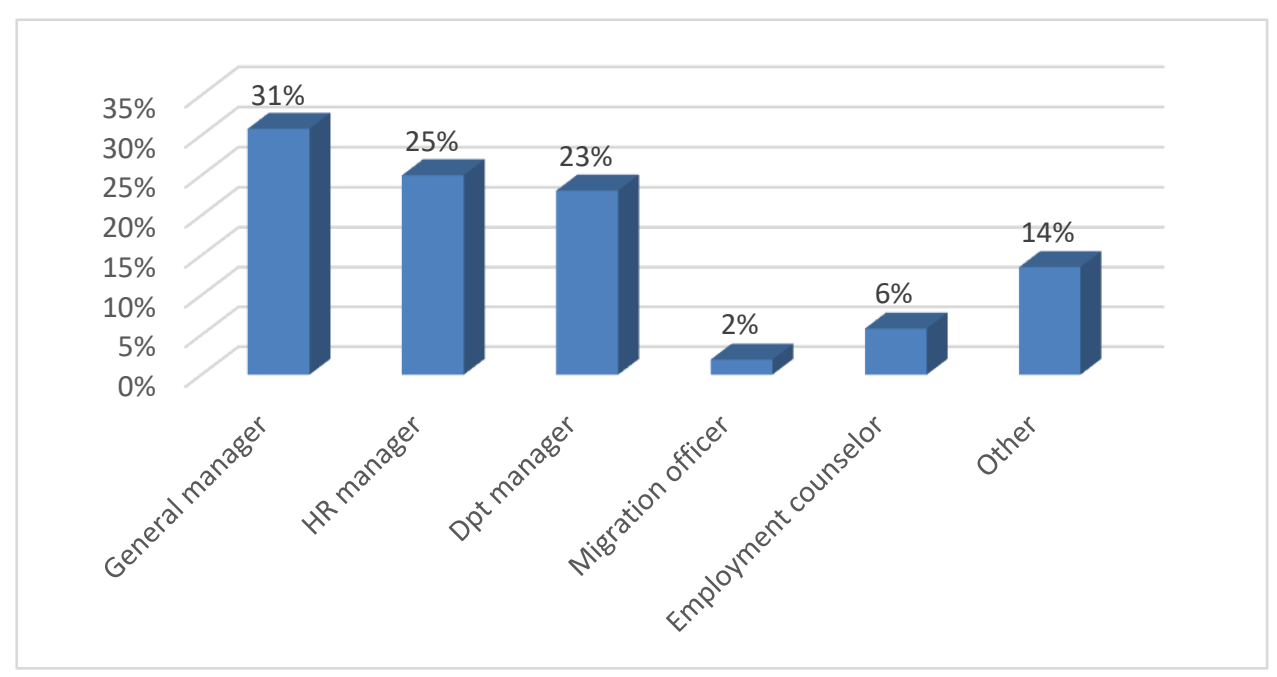

Figure 4. Respondents' position in the organization

As to the position of the person responding to the survey in the organisation, $31 \%$ were General Managers. Other professional roles of the participants were distributed as follows: Human Resources Managers/Officers (25\%), Department Managers/ Officers (23\%), Career Counselling Coordinators (6\%), Migration's Officers (2\%), as well as Owners, Researchers (recorded as Others) (14\%) were also involved (Figure 4).

\subsubsection{Migrant Groups' Characteristics}

Ninety-six (96) people participated in the survey with a response rate at $48 \%$.

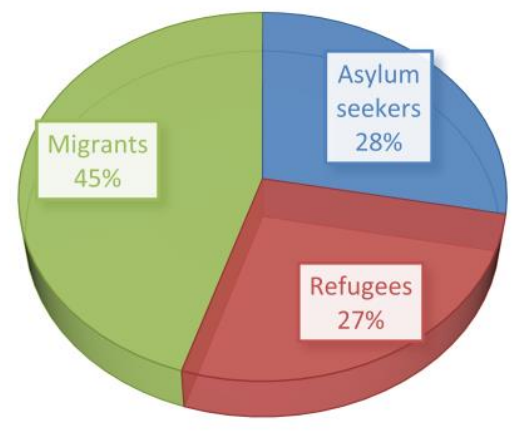

Figure 5. Migration Status

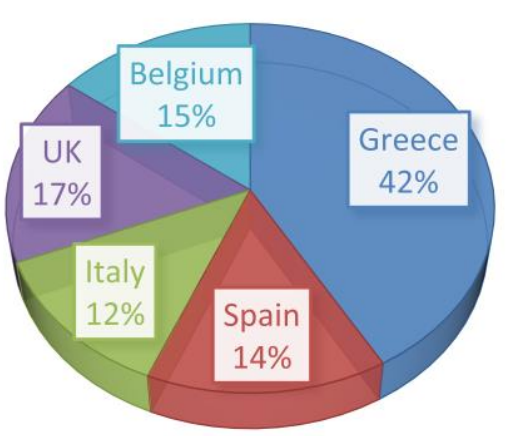

Figure 6. Hosting country

Regarding their status, $45 \%$ were migrants, $28 \%$ asylum seekers and $27 \%$ refugees. With respect to the host countries, $42 \%$ of the participants are in Greece, $17 \%$ in the United Kingdom, $15 \%$ in Belgium \& Spain and $13 \%$ in Italy (Figures $5 \& 6$ ).

There is almost equal representation between men (56\%) and women (44\%), with 50\% of them being 30-45 years old, $33 \% 18-29,15 \% 45-60$ and only $2 \%$ under 18 years old. Regarding the region of origin, most of them come from Africa (30\%), Asia (28\%) and Middle East (26\%).

The main reasons of migration included persecution and poor human rights or freedom and life threatening situations in the country of origin (23\%), poor living conditions (18\%), internal conflict and war (18\%), family reunification $(13 \%)$ as well as willingness to find a better quality of life $(11 \%)$. 
Regarding the participants' skills level, 33\% of them are semi-skilled, $20 \%$ are skilled, whereas $22 \%$ are low-skilled, highly-skilled at $14 \%$ and $11 \%$ are unskilled. As to migrant/asylum seekers/refugees' current status of employment, $55 \%$ of them are employed while $45 \%$ are unemployed who are willing to find a job.

\section{Results}

\subsection{Employers'Results}

The survey consisted of 70 statements describing NADINE Universal skills and sub-skills, which participants were requested to evaluate in a scale from 1-4 (where 1= Not important and $4=$ Extremely important), defining the importance of these skills in the process of employing workers, especially with migrant, asylum seeker, refugee background. Also, the employers were asked about their criteria for employing a migrant/ refugee/ asylum seeker and the usefulness of an online skill assessment tool.

Table 2. Descriptive statistics of 10 Universal Skills according to employers

\begin{tabular}{|c|c|c|c|}
\hline & $\mathrm{N}$ & $\mathrm{M}$ & SD \\
\hline Interpersonal skills & 121 & 3.25 & 0.38 \\
\hline Social Interaction & 121 & 3,55 & 0,53 \\
\hline coping with authority & 122 & 3.40 & 0.59 \\
\hline Conscientiousness & 122 & 3.33 & 0.61 \\
\hline Team working & 122 & 3.64 & 0.58 \\
\hline Intercultural competence & 122 & 3.46 & 0.55 \\
\hline Extraversion & 122 & 3.01 & 0.58 \\
\hline Personal skills & 122 & 3.13 & 0.31 \\
\hline Adaptability & 122 & 3.66 & 0.57 \\
\hline Reliability & 122 & 3.27 & 0.37 \\
\hline Willingness to learn & 122 & 3.00 & 0.41 \\
\hline Stress tolerance & 122 & 3.20 & 0.34 \\
\hline Language learning aptitude \& literacy skills & 121 & 3.09 & 0.44 \\
\hline Organizational skills & 122 & 3.04 & 0.40 \\
\hline Work efficiency & 122 & 2.94 & 0.47 \\
\hline Time management & 122 & 3.43 & 0.49 \\
\hline Organisation & 122 & 2.92 & 0.51 \\
\hline ICT Skills & 118 & 3.03 & 0.82 \\
\hline Technical - manual skills & 122 & 3.00 & 0.74 \\
\hline Dexterity & 122 & 3.00 & 0.94 \\
\hline Accuracy & 122 & 3.25 & 0.60 \\
\hline Spatial Ability & 122 & 2.94 & 0.90 \\
\hline Cognitive - Analytical skills & 119 & 2.62 & 0.57 \\
\hline Observation & 122 & 2.70 & 0.54 \\
\hline Decision making & 122 & 2.62 & 0.64 \\
\hline Problem solving & 122 & 2.61 & 0.58 \\
\hline Entrepreneurial - Intrapreneurial skills & 122 & 2.61 & 0.49 \\
\hline Managerial skills & 122 & 2.67 & 0.55 \\
\hline Risk tolerance & 122 & 2.46 & 0.51 \\
\hline Creativity & 122 & 2.73 & 0.73 \\
\hline Initiative & 122 & 2.57 & 0.74 \\
\hline Leadership & 122 & 2,74 & 0,72 \\
\hline Numeracy Skills & 122 & 2.60 & 0.59 \\
\hline Mechanical skills & 111 & 2.34 & 0.73 \\
\hline
\end{tabular}

Through a deeper analysis of Table 2, it is obvious that among all scales-subscales of the NADINE universal skills framework the most important according to the employers are: Interpersonal skills: with emphasis on "team working" ( $\mathrm{M}=3.64)$, "social interaction" $(\mathrm{M}=3.55)$, "intercultural competence" $(\mathrm{M}=3.46)$, "coping with authority" $(\mathrm{M}=3.40)$, "conscientiousness" $(\mathrm{M}=3.33)$ and "extraversion" $(\mathrm{M}=3.01)$,

Personal skills and especially "adaptability" $(M=3.66)$, "reliability" $(M=3.28)$, "stress tolerance" $(M=3.20)$ and "willingness to learn" $(\mathrm{M}=2.99)$. Language learning aptitude \& literacy skills, Organizational skills: all the dimensions of the skill, namely "time management" $(M=3.34)$, "work efficiency" $(M=2.94)$ and "organization" $(\mathrm{M}=2.92)$,

ICT skills and Technical - manual skills: focusing on "dexterity" $(M=3.00)$ and "accuracy" $(M=3.25)$. The findings of this research are in accordance with EU Skills Panorama data (2020), where adaptability, which is a core personal skill and team working, a core interpersonal skill, as well as language and ICT skills are the most required 
skills in EU.

In order to explore whether there is a statistically significant difference among the employers of different countries regarding the importance of skills, we conducted a one-way Analysis of Variance (ANOVA). The analysis revealed two significant differences on hard skills: on ICT skills $[\mathrm{F}(4,113)=5.247 \mathrm{p}<0.001]$ and on mechanical skills $[\mathrm{F}$ $(4,106)=3.583, \mathrm{p}<0.01]$. The subsequent Tukey's HSD criterion specified where differences existed. Regarding Mechanical skills, employers from Greece $(M=2.2 .66)$ and $U K(m=2.58)$ rated higher the importance of the skill than employers from Belgium $(\mathrm{m}=2.07)$.

The results are in line with the expected future working trends according to the EU Skills Panorama data on future employment growth over the period 2018-2030. Specifically, in Greece manufacturing will be growing, while in UK skill shortages in the engineering sector are reported, which explains the need for mechanical skills in these countries. Furthermore, employers from UK $(\mathrm{m}=3.45)$ and Spain $(\mathrm{m}=3.40)$ evaluated higher the importance of ICT skills in comparison to other countries' employers, which is confirmed by the expected skill shortages in IT/computing occupations, while in Spain the employment is expected to grow till 2030 driven by service sectors, such as ICT services (Skills Panorama, 2020). On the other hand, no significant difference was found concerning any of the soft skills.

Table 3. Descriptive statistics of criteria to employ migrants/ refugees according to employers

\begin{tabular}{|c|c|c|c|c|c|c|}
\hline Criteria & Country & $\mathrm{M}$ & SD & $\mathrm{F}$ & $\mathrm{df}$ & $\mathrm{p}$ \\
\hline \multirow{6}{*}{ Basic skills } & Greece & 3.38 & 0.56 & \multirow{6}{*}{1.939} & 4 & \multirow{6}{*}{$\mathrm{ns}$} \\
\hline & UK & 3.29 & 0.61 & & 117 & \\
\hline & Belgium & 3.49 & 0.49 & & & \\
\hline & Spain & 3.45 & 0.73 & & & \\
\hline & France & 3.00 & 0.82 & & & \\
\hline & Total & 3.31 & 0.66 & & & \\
\hline \multirow{6}{*}{ Soft skills } & Greece & 3.27 & 0.83 & \multirow[t]{2}{*}{1.115} & 4 & \multirow[t]{6}{*}{ ns } \\
\hline & UK & 3.25 & 0.55 & & 117 & \\
\hline & Belgium & 3.45 & 0.60 & \multirow{10}{*}{1.487} & & \\
\hline & Spain & 3.19 & 0.75 & & & \\
\hline & France & 2.99 & 0.79 & & & \\
\hline & Total & 3.24 & 0.73 & & & \\
\hline \multirow{6}{*}{ Hard skills } & Greece & 3.08 & 0.74 & & 4 & \multirow[t]{6}{*}{$\mathrm{ns}$} \\
\hline & UK & 2.99 & 0.71 & & 117 & \\
\hline & Belgium & 3.39 & 0.50 & & & \\
\hline & Spain & 2.98 & 0.70 & & & \\
\hline & France & 2.92 & 0.88 & & & \\
\hline & Total & 3.01 & 0.83 & & & \\
\hline \multirow{6}{*}{ work experience } & Greece & 2.50 & 0.57 & \multirow[t]{6}{*}{1.969} & 4 & \multirow[t]{6}{*}{ ns } \\
\hline & UK & 2.80 & 0.41 & & 117 & \\
\hline & Belgium & 2.64 & 0.58 & & & \\
\hline & Spain & 2.38 & 0.50 & & & \\
\hline & France & 2.57 & 0.53 & & & \\
\hline & Total & 2.59 & 0.53 & & & \\
\hline \multirow{6}{*}{ Educational certificates } & Greece & 2.35 & 0.86 & \multirow[t]{6}{*}{1.366} & 4 & \multirow[t]{6}{*}{ ns } \\
\hline & UK & 2.20 & 0.82 & & 117 & \\
\hline & Belgium & 2.41 & 1.05 & & & \\
\hline & Spain & 2.25 & 1.01 & & & \\
\hline & France & 1.81 & 0.95 & & & \\
\hline & Total & 2.31 & 0.99 & & & \\
\hline
\end{tabular}

The data analysis revealed the criteria of employers when employing migrants/ refugees/ asylum seekers are mainly the basic skills $(M=3.31)$, soft skills $(M=3.24)$ and hard skills $(M=3.01)$, while educational certificates got the lowest score $(\mathrm{M}=2,31)$, which is common among all employers' countries (table 3$)$. It is worth mentioning that educational certificates are still considered to be important, but less important than the basic/soft/hard skills, which seems logical as employers first look at basic, hard and soft skills needed for a job position and then select further on individuals' educational credits. But even more in the case of migrant populations, certifications and formal qualifications are most times hard to be provided due to forced migration. 


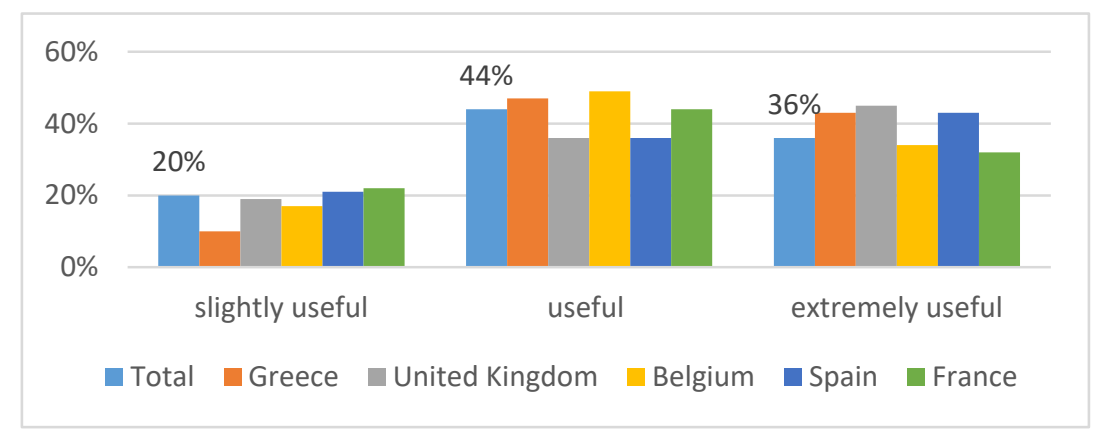

Figure 7. Usefulness of an online tool assessing migrants'/ refugees'/ asylum seekers' skills according to employers

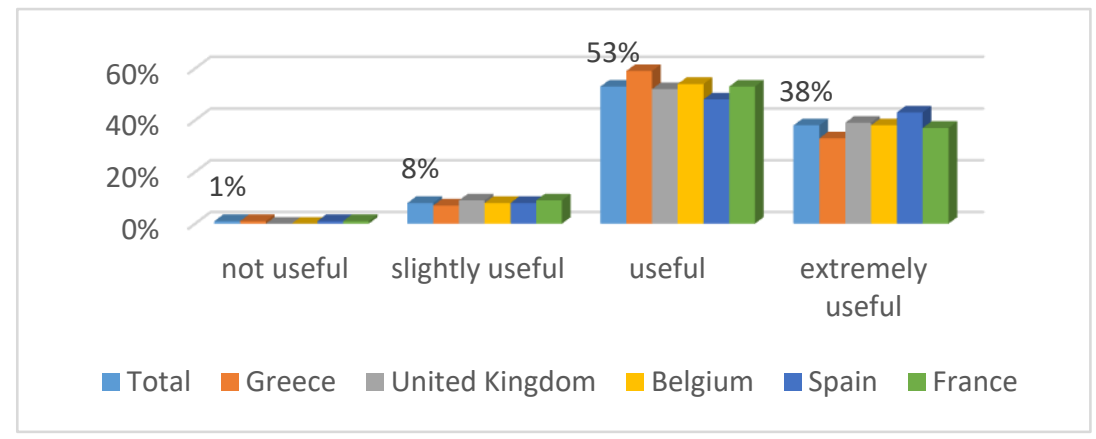

Figure 8. Usefulness for employers of an online tool providing skill's profiling of migrants/ refugees/ asylum seekers workers

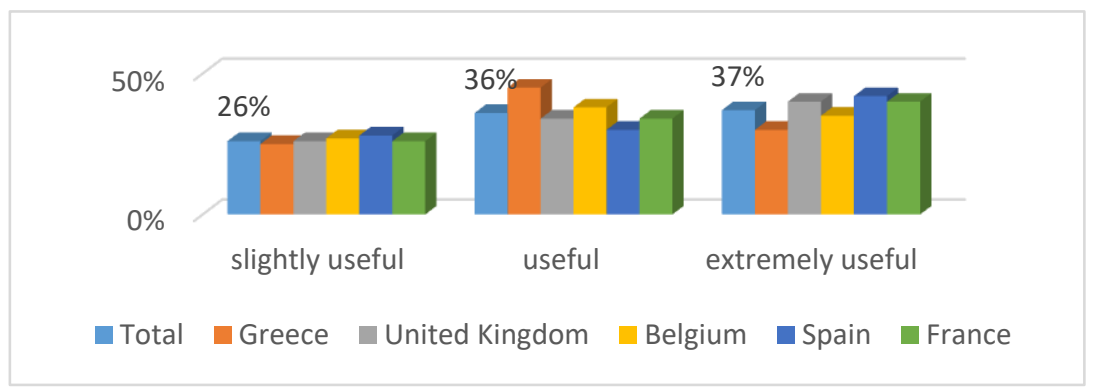

Figure 9. Usefulness for employers of an online tool linking skills profiles of migrants/refugees/ asylum seekers to occupations

Additionally, the importance of the development of an online tool assessing the hard /soft skills of migrant refugee- asylum seeker jobseekers, to provide a full hard/soft skills' profiling and link skills profiles to the most suitable professional occupations or potential employment positions is highly acknowledged by the employers and stakeholders participating in the NADINE survey. Among the survey respondents, $80 \%$ stated that an online tool to assess migrant - refugee candidates' hard /soft skills is useful or extremely useful, while $91 \%$ of them consider a tool providing skills' profiling extremely useful or useful and lastly, an online assessment tool to link migrants' refugees' skills profiles to the most suitable occupations or employment positions in the organization is considered useful or extremely useful by $73 \%$ of the participants.

\subsection{Migrant Groups' Results}

In order to record the opinion of migrants/ refugees/ asylum seekers on the skills that employers request in labour market, they were asked to evaluate 70 statements describing NADINE Universal skills and sub-skills and 5 criteria for finding a job, in a scale from 1-4 (where $1=$ Not important and $4=$ Extremely important). The data analysis yielded the following results. 
Table 4. Descriptive statistics of 10 Universal Skills according to migrants/ refugees/ asylum seekers

\begin{tabular}{|c|c|c|c|}
\hline & $\mathrm{N}^{1}$ & $\mathrm{M}^{2}$ & $\mathrm{SD}^{3}$ \\
\hline Language learning aptitude \& literacy skills & 96 & 3.52 & .45 \\
\hline Interpersonal skills & 94 & 3.22 & .41 \\
\hline Social interaction & 96 & 3.29 & .44 \\
\hline Coping with authority & 96 & 3.21 & .65 \\
\hline Conscientiousness & 94 & 3.21 & .56 \\
\hline Extraversion & 96 & 3.28 & .64 \\
\hline Teamworking & 96 & 3.37 & .64 \\
\hline Intercultural competence & 96 & 3.22 & .63 \\
\hline Organizational skills & 96 & 3.22 & .40 \\
\hline Work efficiency & 96 & 3.20 & .50 \\
\hline Time management & 96 & 3.30 & .48 \\
\hline Organisation & 96 & 3.19 & .43 \\
\hline Cognitive - Analytical skills & 96 & 3.02 & .46 \\
\hline Decision making & 96 & 3.11 & .40 \\
\hline Problem solving & 96 & 2.97 & .57 \\
\hline Observation & 96 & 2.94 & .91 \\
\hline Personal skills & 96 & 3.02 & .51 \\
\hline Adaptability & 96 & 3.07 & .68 \\
\hline Reliability & 96 & 3.23 & .54 \\
\hline Willingness to learn & 96 & 3.09 & .51 \\
\hline Stress tolerance & 96 & 2.70 & .83 \\
\hline ICT Skills & 94 & 3.01 & .38 \\
\hline Entrepreneurial - Intrapreneurial skills & 96 & 2.79 & .72 \\
\hline Managerial skills & 96 & 2.39 & 1.02 \\
\hline Risk tolerance & 96 & 2.55 & .89 \\
\hline Creativity & 96 & 2.81 & .97 \\
\hline Initiatives & 96 & 2.35 & .98 \\
\hline Leadership & 96 & 3.00 & .50 \\
\hline Technical - manual skills & 96 & 2.71 & .62 \\
\hline Dexterity & 96 & 2.63 & .71 \\
\hline Accuracy & 96 & 2.96 & .74 \\
\hline Spatial Ability & 96 & 2.60 & .91 \\
\hline Numeracy Skills & 96 & 2.61 & .49 \\
\hline Mechanical skills & 94 & 2.59 & .64 \\
\hline
\end{tabular}

In reference to the 10 selected universal skills and 25 sub-skills of the NADINE framework, it came out that for our sample all those 10 skills are important for their integration in labour market, and more specifically they rated the "Language learning aptitude" $(\mathrm{M}=3.52)$ higher than all other skills, while of high importance they think that are also "Interpersonal skills" \& "Organizational skills" (M=3.22), "Cognitive skills" and "Personal skills" $(\mathrm{M}=3.02)$ and "ICT skills" (M=3.01) (Table 4). The different groups of the participants (asylum seekers, refugees, migrants) seem to have common opinion on the importance of the aforementioned skills and their subskills, with only one exception: ICT skills $[\mathrm{F}(2,77)=7,032, \mathrm{p}<0.005]$, where migrants $(\mathrm{M}=3.16)$ rated higher this skill in comparison to the other two groups $(\mathrm{M}=2.90 \& \mathrm{M}=2.85)$.

\footnotetext{
${ }^{1}$ Total Number of participants

${ }^{2}$ Mean

${ }^{3}$ Standard Deviation
} 
Table 5. Descriptive statistics and one-way ANOVA results regarding the criteria of migrants/ refugees/ asylum seekers recruitment in the hosting country based on migration status

\begin{tabular}{|c|c|c|c|c|c|c|c|}
\hline Criteria & Group & $\mathrm{N}$ & $\mathrm{M}$ & SD & $\mathrm{df}$ & $\mathrm{F}$ & $\mathrm{p}$ \\
\hline \multirow[t]{4}{*}{ Educational certificates } & migrant & 43 & 3.00 & 1.04 & 2 & .914 & $\mathrm{~ns}$ \\
\hline & refugee & 26 & 3.14 & 0.91 & 93 & & \\
\hline & asylum seeker & 27 & 2.78 & 0.95 & & & \\
\hline & Total & 96 & 2.97 & 0.98 & & & \\
\hline \multirow[t]{4}{*}{ Basic skills } & migrant & 43 & 3.15 & 0.89 & 2 & 1.499 & ns \\
\hline & refugee & 26 & 2.90 & 0.44 & 93 & & \\
\hline & asylum seeker & 27 & 3.19 & 0.40 & & & \\
\hline & Total & 96 & 3.09 & 0.68 & & & \\
\hline \multirow[t]{4}{*}{ Hard skills } & migrant & 43 & 3.21 & 0.91 & 2 & 2.119 & $\mathrm{~ns}$ \\
\hline & refugee & 26 & 3.00 & 0.45 & 93 & & \\
\hline & asylum seeker & 27 & 2.81 & 0.87 & & & \\
\hline & Total & 96 & 3.04 & 0.81 & & & \\
\hline \multirow[t]{4}{*}{ Soft skills } & migrant & 43 & 3.09 & 0.97 & 2 & .002 & ns \\
\hline & refugee & 26 & 3.10 & 0.77 & 93 & & \\
\hline & asylum seeker & 27 & 3.10 & 0.62 & & & \\
\hline & Total & 96 & 3.09 & 0.82 & & & \\
\hline \multirow[t]{4}{*}{ Work experience } & migrant & 43 & 3.12 & 0.91 & 2 & .716 & ns \\
\hline & refugee & 26 & 2.95 & 0.50 & 93 & & \\
\hline & asylum seeker & 27 & 3.19 & 0.68 & & & \\
\hline & Total & 96 & 3.09 & 0.75 & & & \\
\hline
\end{tabular}

Additionally, migrants/ refugees/ asylum seekers claimed the "basic skills" (M=3,09), "soft skills" (M=3.09), "work experience" $(\mathrm{M}=3.09)$ and "hard skills" $(\mathrm{M}=3.04)$ are considered as crucial for their recruitment in the hosting countries (table 5). The results are common for all the three groups (asylum seekers, migrants, refugees) as there was no statistically significant difference found among these different groups based on migration status.

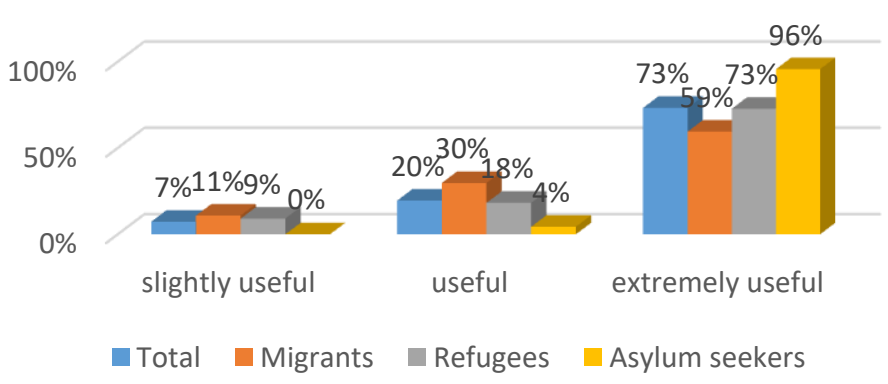

Figure 10. Usefulness of an online tool assessing migrants'/ asylum seekers'/ refugees' skills

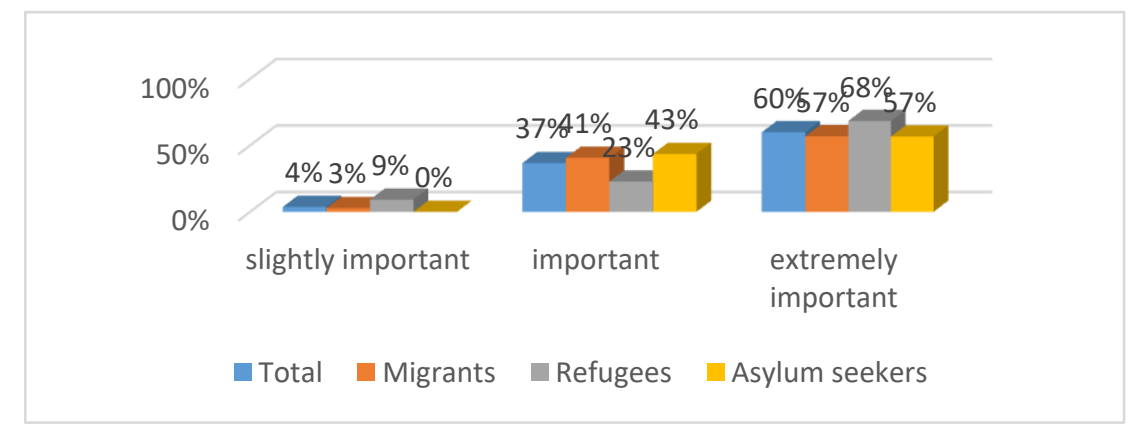

Figure 11. Importance of an online tool providing skill's profiling of migrants/ asylum seekers/ refugees workers 


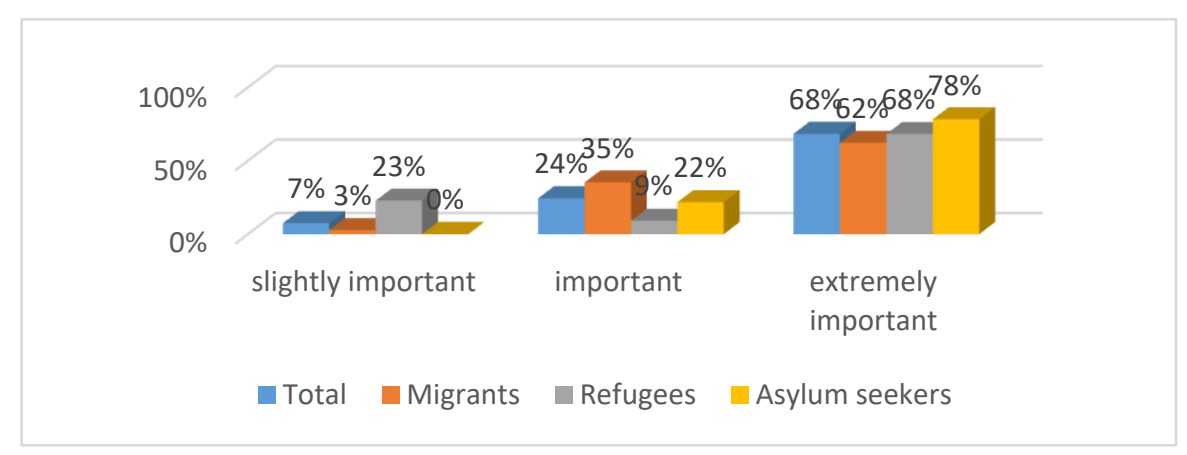

Figure 12. Importance of an online tool linking skills profiles of migrants/ asylum seekers/ refugees to occupations/ positions

Finally, the usefulness of an online tool assessing the hard/ soft skills of migrant-refugee job seekers was highlighted by all participants, as $93 \%$ of them consider it as useful and/ or extremely useful. At the same mood, the majority of participants $(97 \% \& 92 \%)$ consider an online tool for skills' profiling and linking skills profiles to the most suitable professional occupations important and/ or extremely important. These two last findings are not of a surprise, as the inability to have qualifications recognized or skills validated still remains an issue, as it restricts access to certain jobs and leads to overqualification in lower-skilled positions (IOM, 2020). Therefore, a skill assessment tool and the matching between skills and occupations could enable the migrant groups to prove their potential and get a suitable for them job.

\section{Discussion}

While labour market integration is prioritized for migrant job seekers, however, many of them find it extremely difficult to have their skills and experience recognized (International Labour Organization, 2017a). Despite that migrant groups have generally developed either in their home country or in the hosting countries competencies and abilities necessary for integration into the labour market, often these are not formally mapped, assessed, certified or acknowledged. This results in severe skills-related underemployment and a loss of economic benefits both for them and the countries of destination or/ and origin.

Starting from this widely acknowledged existing gap, the NADINE project has developed the Universal Skills Framework for migrants, asylum seekers \& refugees (Table 1), based mainly in the literature review and desk research, with the aim to provide a commonly understood matrix to enable migrant skills identification and assessment, which is an important challenge for all destination countries in the process of embracing migrants' potential. All major hard and soft skills that are universally considered necessary for employability are included in the framework as meaningful benchmarks for migrant groups covering the most highly valued business-oriented qualities in the globalised labour market. The universality of skills and competencies required for the employability of individuals in the globalized labour market also applies to migrants and refugees, who face the same situation in the European labour market as native workers and need special skills and abilities to adapt to the new reality, characterized by a wealth of new information and rapid change (ILO, 2017a; OECD, 2015. Dragos-Paul, 2014).

As the views of end-users of a product are always valuable, representatives from enterprises, public authorities, NGOs, and other entities as well as a sample of migrants, refugees and asylum seekers were consulted in the process, so as to validate the suitability and importance of the selected skills for migrants, asylum seekers and refugees' inclusion in the host communities and local labour market. In a nutshell, the overall final results generally confirmed the suitability and the significance of the skills and sub-skills included in the Universal Skills Framework.

As skills have a crucial role in migrants' and refugees' social and labour market integration, the development of large-scale and systematic procedures for skills assessment, that include valid and reliable skills assessment tools that allow for fully mapping of the cognitive, emotional and social qualities and abilities of an individual is highly recommended. The inability to have qualifications recognized or skills validated also remains an issue and an objective skill assessment could be a solution for proving migrant groups' qualifications and potential. Both migrant groups and employers were in favour of an online assessment tool for identifying and assessing soft and hard skills, agreeing that this approach can facilitate work integration procedures and, simultaneously, enhance the end-users' self-esteem and employability. Overall, the creation of suitable valid and reliable skills identification and assessment tools will facilitate the measurement of selected transferable soft skills and hard skills, which are considered important for migrants' social and labour market integration. This is in line with a relevant recent study that reported that employers in Europe have a 
good, equally and strong perception regarding a sustainable and experimental innovative online tool for the continuous assessment of skills to support employability (Gabor et al., 2019).

With this in mind, skills assessment methods and tools should map the skills included in the Framework and required by an individual to perform adequately and flexibly in both familiar and unfamiliar situations and/or in cultural diverse global workplaces. This way tools can assess and identify the broad spectrum of migrants, asylum seekers' and refugees' inclinations and abilities within the globalized market, allowing for developing untapped skills.

Although, the skills included in the Framework are considered universal and important for labour market integration, it seems that there are slight differences among countries on the level of importance of hard skills (like mechanical, ICT, technical etc) due to the national labour market trends, which are in accordance with the EU Skills Panorama data on future employment growth over the period 2018-2030. Therefore, it is important the skill assessment procedures to make a match between needs and skills, in order to suggest the best match in terms of optimal integration location for the end user, considering migrant group's skills profile and the EU countries work-related data. The need for matching skills with job categories and labour market needs, has also been identified from employers and migrant groups, as well. Therefore, skill assessment procedures should provide concrete, accurate, reliable, and personalised profiling results, that can be useful to employers in selecting appropriate employees according to their needs and available job profiles, to educational institutions and hosting organisations in designing trainings and services matching with the needs of migrant groups, as well as to migrant groups helping them to identify, improve, document and certify their competences, enabling social and labour market integration. This process is also in line with adult migrant/refugees integration policies listing as issues of first priority the provision of skill-based complementary pathways and opportunities for resettlement based on the matching of refugees' skills with labour market needs of the host countries (David \& Katsikis, 2019; David \& Wagner, 2019; Cedefop, 2018).

Overall, the NADINE Universal Skills Framework could be a basis for tools and methods to assess migrants, asylum seekers and refugees' skills and for further interventions (training courses, matching skills to labour market needs and jobs) to boost migrants/refugees/asylum seekers integration. Such interventions at national level would be useful for both individuals and employers, while public bodies, certification bodies and other bodies in EU countries could also benefit from the use of skills assessment tools in the recruitment process or as part of skills recognition strategies. In this way, employers would be able to select the right candidates according to their needs, while educational institutions could design effective training programs that match the real needs of migrants, asylum seekers and refugees. Undoubtedly, these practices will help increase the competitiveness of businesses and create inclusive societies in host countries, as well as enhance self-esteem and self-efficacy, employability, individual well-being and the readiness of migrant groups to take advantage of opportunities in the new social and work environment.

Nonetheless, we have to mention that our study has limitations. Sample sizes were rather modest, especially in the case of migrant groups and further research is required to ensure the representativeness of the results with larger samples involving migrant groups in more hosting countries. The importance of an online skill assessment and matching tool that has been pointed out in our study from both users (employers and migrant groups), suggests the need for the development of cultural adapted skill assessment tools and further exploration of innovative methodologies that can be implemented in the skill assessment of migrant groups.

\section{Notes}

\section{Funding}

This article is part of the NADINE project, which has received funding from the European Union's Horizon 2020 research and innovation programme under grant agreement No 822601.

\section{References}

Baert, S., \& Vujić, S. (2016). Immigrant volunteering: A way out of labour market discrimination? Economics Letters, 146, 95-98. https://doi.org/10.1016/j.econlet.2016.07.035

Bardy, R., \& Rubens, A., \& Eberle, P. (2017). Soft Skills and Job Opportunities of Migrants: Systemic Relationships in the Labor Market. Business Ethics and Leadership, 1, 5-21. https://doi.org/10.21272/bel.1(4).5-21.2017

Bernhard-Oettel, C., \& Näswall, K. (2015). Career continuance and transfer of competencies after job transitions: Insights from a Swedish study. In Handbook of Research on Sustainable Careers. Edited by Beatrice van der Heijden and Ans De Vos. Cheltenham: Edward Elgar, pp. 381-97. https://doi.org/10.4337/9781782547037.00030

Brewer, L. (2013). Enhancing youth employability: What? Why? and How? Guide to core work skills /International Labour Office, Skills and Employability Department-Geneva: ILO, 2013. Retrieved from https://www.ilo.org/wcmsp5/groups/public/---ed_emp/---ifp_skills/documents/publication/wcms_213452.pdf 
Cameron, R., Farivar, F., \& Dantas, J. (2019). The unanticipated road to skills wastage for skilled migrants: the non-recognition of overseas qualifications and experience (ROQE). Labour \& Industry: a journal of the social and economic relations of work, 29(1), 80-97. https://doi.org/10.1080/10301763.2018.1554098

Cedefop. (2013) Piloting a European employer survey on skill needs, Illustrative findings. Luxembourg: Publications Office of the European Union. European Centre for the Development of Vocational Training (Cedefop).

Cedefop. (2018). Insights into skill shortages and skill mismatch: learning from Cedefop's European skills and jobs survey. Luxembourg: Publications Office. Cedefop reference series; No 106. https://doi.org/ 10.2801/645011

Cedefop. (2020). Skills Panorama glossary. Retrieved from https://skillspanorama.cedefop.europa.eu/en/glossary\#

Council of Europe. (2016). Competences for democratic culture - Living together as equals in culturally diverse democratic societies. Strasbourg: Council of Europe. ISBN 978-92-871-8237-1

Dall'Amico, E., \& Verona, S. (2015). Cross-Country survey on soft skills required by companies to medium/high skilled migrants - Methodological approach for a common framework of Soft Skills at work. Valorize High Skilled Migrants (2014-1-IT02-KA204-003515), Ceipiemonte S.c.p.a., Italy.

David, R., \& Katsikis, I. (2019). Refugee skills and labour market needs: How matching can support lawful adult refugee mobility. Department for learning and employability, European Centre for the Development of Vocational Training (Cedefop). Retrieved from https://www.cedefop.europa.eu/files/8131_en.pdf

David, R., \& Wagner, M. (2019). Refugees and the labour market: the role of skills in facilitating access. Cedefop, Skills Panorama. Retrieved from https://skillspanorama.cedefop.europa.eu/en/blog/refugees-and-labour-market-role-skills-facilitating-access

Dragos-Paul, P. (2014). Online Tool for Soft Skills Evaluation and Employee Management, Romanian Economic Business Review, 8(2), 410-419.

Eggenhofer-Rehart, P. M., Latzke, M., Pernkopf, K., Zellhofer, D., Mayrhofer, W., \& Steyrer, J. (2018). Refugees' career capital welcome? Afghan and Syrian refugee job seekers in Austria. Journal of Vocational Behavior, 105, 31-45. https://doi.org/10.1016/j.jvb.2018.01.004

European Commission. (2017). Council Recommendation of 22 May 2017 on the European Qualifications Framework for lifelong learning and repealing the Recommendation of the European Parliament and of the Council of 23 of April of 2008 on the establishment of the European Qualifications Framework for lifelong learning. Retrieved from https://ec.europa.eu/ploteus/sites/eac-eqf/files/en.pdf

European Commission. (2018a). Council Recommendation of 22 May 2018 on key competences for lifelong learning (Text with EEA relevance.) ST/9009/2018/INIT OJ C 189, 4.6.2018, p. 1-13 (BG, ES, CS, DA, DE, ET, EL, EN, FR, $H R, \quad I T, \quad L V, \quad L T, \quad H U, \quad M T, \quad N L, \quad P L, \quad P T, \quad R O, \quad S K, \quad S L, \quad F I, \quad S V)$. Retrieved from https://eur-lex.europa.eu/legal-content/EN/TXT/PDF/?uri=CELEX:32018H0604(01)\&from=EN

European Commission. (2018b). The digital competence framework for citizens with eight proficiency levels and examples of use. Luxembourg: Publications office of the European Union.

European Commission. (2019a). The European Entrepreneurship Competence Framework. Luxembourg: Publications office of the European Union.

European Commission. (2019b). ESCO handbook: European Skills, Competences, Qualifications and Occupations, Directorate-General for Employment, Social Affairs and Inclusion, European Union. Retrieved from https://ec.europa.eu/esco/portal/document/en/0a89839c-098d-4e34-846c-54cbd5684d24

Gabor, M. R., Blaga, P., \& Matis, C. (2019). Supporting Employability by a Skills Assessment Innovative Tool—Sustainable Transnational Insights from Employers. Sustainability, 11(12), 3360. https://doi.org/10.3390/su11123360

International Labour Organization. (2015). Regional Model Competency Standards: core competencies / Regional Skills Programme, ILO Regional Office for Asia and the Pacific. Bangkok: ILO. https://doi.org/10.30875/60123dd4-en

International Labour Organization. (2017a). Addressing governance challenges in a changing labour migration landscape. Report IV, (ILC, 106th session, Geneva).

International Labour Organization. (2017b). 'How To Facilitate The Recognition Of Skills Of Migrant Workers Guide For Employment Service Providers".

International Organization for Migration. (2020). World migration report 2020. Switzerland: IOM.

Keltner, D., Kogan, A., Piff, P. K., \& Saturn, S. R. (2014) The sociocultural appraisals, values, and emotions (SAVE) 
framework of prosociality: core processes from gene to meme. Annu. Rev. Psychol., 65, 425-460. https://doi.org/10.1146/annurev-psych-010213-115054

Liu-Farrer, G, \& Shire, K. (2020). Who are the fittest? The question of skills in national employment systems in an age of global labour mobility, Journal of Ethnic and Migration Studies.

https://doi.org/10.1080/1369183X.2020.1731987

Louis, W. R., Thomas, E., Chapman, C. M., Achia, T., \&Droogendyk, L. (2019). Emerging research on intergroup prosociality: Group members' charitable giving, positive contact, allyship, and solidarity with others. Social and Personality Psychology Compass, e12436. https://doi.org/ 10.1111/spc3.12436

Mancinelli, S., Mazzanti, M., Piva, N., \& Ponti, G. (2010). Education, reputation or network? Evidence on migrant workers' employability. The Journal of Socio-Economics, 39, 64-71. https://doi.org/10.1016/j.socec.2009.08.002

Marangozov, R. (2017). Background Paper: The Recognition of 'soft' and informal skills. ESF Transnational Platform. Retrieved from https://ec.europa.eu/esf/transnationality/filedepot_download/1297/1434

Mucci, N., Traversini, V., Giorgi, G., Tommasi, E., De Sio, S., \&Arcangeli, G. (2019). Migrant workers and psychological health: A systematic review. Sustainability 2020, 12, 1-28. https://doi.org/ 10.3390/su12010120

OECD. (2005). The definition and selection of key competencies: Executive summary, OECD Publishing. Retrieved from https://www.oecd.org/pisa/35070367.pdf

OECD. (2014), Talent. OECD - Learn, Perform, Succeed, Competency Framework, OECD Publishing. Retrieved from https://www.oecd.org/careers/competency_framework_en.pdf

OECD. (2015). Universal Basic Skills: What Countries Stand to Gain, OECD Publishing. ISBN 978-92-64-23483-3

OECD. (2016). The Survey of Adult Skills, PIAAC: Reader's Companion, Second Edition, OECD Skills Studies, OECD Publishing, Paris.

OECD. (2018a). Preparing Our Youth For An Inclusive And Sustainable World - The OECD PISA global competence framework. Retrieved from https://www.oecd.org/pisa/Handbook-PISA-2018-Global-Competence.pdf

OECD. (2018b). The future of Education and Skills 2030. Retrieved from https://www.oecd.org/education/2030/E2030\%20Position\%20Paper\%20(05.04.2018).pdf

Penner, L. A., Dovidio, J. F., Piliavin, J. A., \& Schroeder, D. A. (2005). Prosocial behavior: multilevel perspectives. Annu. Rev. Psychol, 56, 365-392. https://doi.org/10.1146/annurev.psych.56.091103.070141

Př́ívara, A., Rievajová, E., \& Yüceşahin, M. (2019). Labour market disadvantages faced by migrant workers from Czech Republic, Hungary, and Slovakia in Britain. Migration Letters, 16(4), 585-594. https://doi.org/10.33182/ml.v16i4.720

Skills Panorama, (2020). European Commission, Directorate-General for Employment, Social Affairs and Inclusion, Cedefop, the European Centre for the Development of Vocational Training. Retrieved from https://skillspanorama.cedefop.europa.eu/en

Strohmeier, D., Fandrem, H., \& Spiel, C. (2012). The need for peer acceptance and affiliation as underlying motive for aggressive behaviour and bullying others among immigrant youth living in Austria and Norway. Anales de Psicología, 28(3)(octubre), 695-704.

The Adecco Group. (2017). The Soft Skills Imperative. White Paper 1/2017. Retrieved from https://www.adeccogroup.com/wp-content/themes/ado-group/downloads/the-adecco-group-white-paper-the-soft-sk ills-imperative.pdf

UNESCO. (2013). Toward universal learning: a global framework for measuring learning: executive summary. Canada: UNESCO. Retrieved from https://unesdoc.unesco.org/ark:/48223/pf0000225210

UNESCO. (2013a). Intercultural competences: conceptual and operational framework. Paris: UNESCO. Retrieved from https://unesdoc.unesco.org/ark:/48223/pf0000219768

United Nations Department of Economic and Social Affairs (UN DESA). (2019). International Migrant Stock 2019. United Nations, New York. Retrieved from https://www.un.org/en/development/desa/population/migration/data/estimates2/estimates19.asp

Van Riemsdijk, M., Basford, S., \& Burnham, A. (2016). Socio-cultural incorporation of skilled migrants at work: Employer and migrant perspectives. International Migration, 54, 20-34. https://doi.org/10.1111/imig.12221

Wibisono, S., Mirnajafi, Z., Droogendyk, L., Chapman, C. M., Achia, T., Thomas, E. F., \& Louis, W. R. (2019). Teaching 
and learning guide for intergroup prosociality. Social and Personality Psychology Compass, e12473. https://doi.org/10.1111/spc3.12473

\section{Copyrights}

Copyright for this article is retained by the author(s), with first publication rights granted to the journal.

This is an open-access article distributed under the terms and conditions of the Creative Commons Attribution license which permits unrestricted use, distribution, and reproduction in any medium, provided the original work is properly cited. 